\title{
A randomized controlled pilot trial of classroom-based mindfulness meditation compared to an active control condition in sixth-grade children ${ }^{\text {t3 }}$
}

\author{
Willoughby B. Britton a,e,*, Nathaniel E. Lepp ${ }^{\mathrm{a}}$, Halsey F. Niles ${ }^{\mathrm{a}, \mathrm{b}}$, Tomas Rocha ${ }^{\mathrm{a}, \mathrm{c}}$, \\ Nathan E. Fisher ${ }^{\mathrm{a}, \mathrm{e}}$, Jonathan S. Gold ${ }^{\mathrm{a}, \mathrm{d}}$ \\ a Brown University Contemplative Studies Initiative, USA \\ b Benson-Henry Institute for Mind Body Medicine, Massachusetts General Hospital, USA \\ ${ }^{\mathrm{c}}$ Mind \& Life Institute, USA \\ d Moses Brown School, USA \\ e Department of Psychiatry and Human Behavior, Brown University Medical School, USA
}

\section{A R T I C L E I N F O}

\section{Article history:}

Received 18 December 2012

Received in revised form 30 March 2014

Accepted 30 March 2014

Available online 27 April 2014

\section{Keywords:}

Children

Pre-adolescent

Mindfulness meditation

Contemplative education

School

Social and emotional learning

\begin{abstract}
A B S T R A C T
The current study is a pilot trial to examine the effects of a nonelective, classroom-based, teacher-implemented, mindfulness meditation intervention on standard clinical measures of mental health and affect in middle school children. A total of 101 healthy sixth-grade students (55 boys, 46 girls) were randomized to either an Asian history course with daily mindfulness meditation practice (intervention group) or an African history course with a matched experiential activity (active control group). Self-reported measures included the Youth Self Report (YSR), a modified Spielberger State-Trait Anxiety Inventory, and the Cognitive and Affective Mindfulness Measure -Revised. Both groups decreased significantly on clinical syndrome subscales and affect but did not differ in the extent of their improvements. Meditators were significantly less likely to develop suicidal ideation or thoughts of self-harm than controls. These results suggest that mindfulness training may yield both unique and non-specific benefits that are shared by other novel activities.

(c) 2014 Society for the Study of School Psychology. Published by Elsevier Ltd. All rights reserved.
\end{abstract}

\section{Introduction}

Children in the United States face myriad psychological challenges, including depression, anxiety, and attention deficits (Bloom, Dey, \& Freeman, 2006). It is estimated that the prevalence among American youth of a mental disorder resulting in severe impairment is as high as 22.2\% (Merikangas et al., 2010). Not only do many disorders emerge during childhood and adolescence (Costello, Angold, \& Keeler, 1999; Paus, Keshavan, \& Giedd, 2008), but also early symptoms of psychological distress can also be predictive of later episodes of minor and major illnesses (Keenan et al., 2008), and subclinical symptoms of depression during adolescence can predict later episodes in adulthood (Pine, Cohen, Cohen, \& Brook, 1999). For some, adolescence can be a dangerous period, as unmonitored mood problems and stress can lead to self-harming behaviors and suicide (Beautrais, 2003; Laye-Gindhu \& Schonert-Reichl, 2005). Excessive stress during developmental periods can also lead to serious cognitive consequences in adult life

\footnotetext{
Disclosure statement: This was not an industry-supported study. The authors have indicated no financial conflicts of interest.

* Corresponding author at: Department of Psychiatry and Human Behavior, Warren Alpert Medical School at Brown University, 185 Brown St, Providence, RI 02906, USA. Tel.: +1 520245 1855; fax: +1 40148635738.

E-mail address: Willoughby_Britton@Brown.edu (W.B. Britton).

ACTION EDITOR: Jennifer Frank.
} 
(Davidson \& McEwen, 2012; Hedges \& Woon, 2011). Accordingly, pre-adolescence represents a significant window of opportunity during which an intervention can help prevent the development of later life challenges, including a major psychiatric disorder.

It has been argued that schools have become the frontline of the mental health system for children and adolescents (Burns et al., 1995). Many American schools offer a variety of mental health services ranging from acute care to more generalized prevention programs, implemented through full-service school-based health centers, school psychologists, or guidance counselors. However, the availability of such services varies depending upon local resources (Weist, 1997), and there is a consensus that the mental health needs of many children in the United States remain largely unmet, especially among minority groups and the uninsured (Broman, 2012; Costello, Egger, \& Angold, 2005; DeRigne, 2010; Flisher et al., 1997; Kataoka, Zhang, \& Wells, 2002; Kessler et al., 2001; Williams \& Chapman, 2011; Wu, Katic, Liu, Fan, \& Fuller, 2010). Undoubtedly, schools with limited resources would benefit from low cost interventions that are proven to improve student mental health.

Programs that are integrated directly into regular classroom curricula may offer cost-effective alternatives to after-school initiatives, which require additional resources and may not be available to students with competing demands for time, such as jobs or afterschool activities. Programs that are integrated into curricula also present a potential advantage over those offered through health services, which are also not always available to students in impoverished communities. As a result, a variety of classroom-based, teacher-implemented programs have been developed to help prevent the onset of psychological, emotional, behavioral, and social disorders among children (Leaf et al., 1996; Rones \& Hoagwood, 2000). Some school health programs promote health by focusing on general knowledge about care for oneself and others, whereas others teach specific skills to help students lead healthy lifestyles. At least one study (Schlitt et al., 2000) provides evidence that up to around 50\% of school-based mental health centers in the United States offer classroom-based behavior modification programs, which suggests popular support for curriculum-integrated intervention strategies. Furthermore, programs that are integrated into existing curricula offer an indirect advantage in the sense that they may reduce the stigma surrounding the procurement of mental health services. Stigma is a common reason that youth do not seek and receive mental health treatment - by incorporating mindfulness interventions directly into the classroom, students and teachers are given an opportunity to raise and discuss mental health concerns.

Recently, mindfulness meditation has experienced growing popularity as a form of school-based intervention and has been incorporated into educational curricula throughout the United States, both in K-12 schools (Greenberg \& Harris, 2012; Kaiser-Greenland, 2010; Meiklejohn et al., 2012; Mind and Life Education Research Network (MLERN), 2012) and in higher education (Shapiro, Brown, \& Astin, 2011). Mindfulness meditation involves two core activities, the cultivation of attention regulation and emotional equanimity, and has been defined as the process of, "bringing one's complete attention to the present experience on a moment-to-moment basis" (Marlatt \& Kristeller, 1999, p. 68). School-based meditation programs implement simple techniques designed to enhance self-awareness and self-regulation of attention, emotions, and behavior in children and adolescents (Greenberg \& Harris, 2012; MLERN et al., 2012). Primary practices in school-based meditation programs (particularly mindfulness) include directing attention to a specific "attentional anchor" - a focus of attention, such as the sensations of breathing or environmental sounds, that one returns to whenever the mind wanders - in order to cultivate greater clarity and acceptance of moment-to-moment experience. Such programs often adapt practices from mindfulness programs developed for adults, such as Mindfulness-Based Stress Reduction (MBSR), an 8-week stress reduction program that incorporates stress education, group therapy, and meditations drawn from Buddhist traditions (Carboni, Roach, \& Fredrick, 2013; Kabat-Zinn, 1990). Other school-based programs adopt practices such as yoga (Khalsa, Hickey-Schultz, Cohen, Steiner, \& Cope, 2012) and tai chi (Wall, 2005). Interventions can involve daily practice (Beauchemin, Hutchins, \& Patterson, 2008; Schonert-Reichl \& Lawlor, 2010) or be composed of weekly sessions with additional "homework" meditation sessions. Informal meditation practices are also used, which involve incorporating mindful awareness into common activities such as walking, eating, and talking (Meiklejohn et al., 2012).

Empirical studies in adults suggest that meditation practices may have positive impacts on a wide range of conditions that start in adolescence, including anxiety, depression (Grossman, Niemann, Schmidt, \& Walach, 2004; Hofmann, Sawyer, Witt, \& Oh, 2010), and suicidal behavior (Williams, Duggan, Crane, \& Fennell, 2006). Additionally, studies in adults have also found improvements in sustained attention (Jha, Krompinger, \& Baime, 2007; Kaul, Passafiume, Sargent, \& O'Hara, 2010; MacLean et al., 2010; Valentine \& Sweet, 1999), executive function and self-regulation (Chambers, Lo, \& Allen, 2008; Heeren, Van Broeck, \& Philippot, 2009; Ortner, Kilner, \& Zelazo, 2007; Tang, Yang, Leve, \& Harold, 2012; Tang et al., 2007; Zeidan, Johnson, Diamond, David, \& Goolkasian, 2010; Zylowska et al., 2008), which are important markers of risk in children and adolescents. In children and adolescents, poor executive functioning, including self-regulation problems and attention problems, is predictive of a wide range of behavioral and emotional problems, especially depression, anxiety, and suicidality (Moffitt et al., 2011; Tang et al., 2012). Conversely, better executive functioning is associated with greater emotional, behavioral, and health outcomes (Blair \& Peters, 2003; Blair \& Razza, 2007; Carlson, Mandell, \& Williams, 2004; Carlson \& Moses, 2001; Lefevre et al., 2013; Moffitt et al., 2011).

Because of the widespread popularity, application, and scientific study of meditation in adults, there has been much interest and enthusiasm in applying these practices earlier in life, during childhood and adolescence. A few well-designed randomized control trials (RCTs) suggest that mindfulness-based programs may benefit clinical samples of children and adolescents with anxiety, depression (Beauchemin et al., 2008; Biegel, Brown, \& Shapiro, 2009), and attention problems (Semple, Lee, Rosa, \& Miller, 2010; Zylowska et al., 2008).

However, there are serious limitations to the body of mindfulness research on children and adolescent populations (Burke, 2010). In addition to the many pilot trials that suffer from small sample sizes (Bogels, Hoogstad, van Dun, De Shutter, \& Restifo, 2008; Singh et al., 2007), previous studies have often involved clinical samples that preclude generalization to normal adolescent populations (Biegel et al., 2009; Singh et al., 2007; Singh et al., 2010; Zylowska et al., 2008). Such samples include only those children whose symptoms have been severe enough to warrant treatment. Broader interventions for larger, nonclinical groups 
may help to prevent these behaviors before they reach a clinical severity. Another challenge is that studies involving nonclinical adolescent populations conducted in clinics by licensed therapists and clinicians (Saltzman \& Goldin, 2008) run the risk of creating a stigma associated with the treatment's location and may also introduce financial barriers that contribute to substantial selection biases.

In an attempt to resolve such problems, several studies to date have incorporated meditation interventions directly into schools. Paralleling the findings in clinical samples above, RCTs of school-based mindfulness programs also suggest that these programs can improve depression and anxiety (i.e. "internalizing symptoms"), behavior and conduct problems ("externalizing symptoms"), attention and executive function, and affective disturbance in nonclinical samples of children and adolescents (Flook et al., 2010; Mendelson et al., 2010; Napoli, Krech, \& Holley, 2005; Raes, Griffith, Van der Gucht, \& Williams, 2013).

However, research of school-based programs also suffers from methodological limitations. First, these programs are often presented as electives (Foret et al., 2012) or as pull-out sessions with a specialist (e.g., a counselor or psychologist). Like other forms of pull-out programs (e.g., social skills programs), the outcomes from such self-selected or elective programs may lack the degree of generalizability available to programs that are undertaken by an entire class or school. Mindfulness-based programs have most often been taught by independent instructors who are hired externally and not delivered by the children's regular teachers or the school counselor, so there is a lack of evidence suggesting the effectiveness of interventions delivered by class-room teachers during school hours (Fernando \& Keller, 2012; Foret et al., 2012; Napoli et al., 2005). It is possible that interventions not delivered by the regular classroom teacher carry with them an additional potential barrier to delivery, as students may not be as receptive to an outsider as to a teacher they are familiar with and may be unmotivated to participate in extracurricular mindfulness training.

A number of reviews of the effects of mindfulness, meditation (Black, Milam, \& Sussman, 2009; Burke, 2010; Waters, Barsky, Ridd, \& Allen, 2014), and yoga (Birdee et al., 2009) among children offer a high level of enthusiasm tempered by similar conclusions about the poor quality of research. The most recent reports on the state of contemplative education research (Greenberg \& Harris, 2012; MLERN et al., 2012; Waters et al., 2014) emphasize a paucity of methodologically rigorous research. For example, out of the 14 studies of school-based meditation interventions covered in a recent review (Meiklejohn et al., 2012), only 2 were RCTs based in nonclinical school classrooms (Flook et al., 2010; Napoli et al., 2005).

The current pilot study was designed so that the interventions could be delivered by classroom teachers and offered during regular school lessons. In addition, this study's design is one of the few to date where the course containing the intervention was required for all students (avoiding self-selection bias). Additionally, the intervention was delivered in a nonclinical setting and taught by the regular classroom teacher during normal lessons and was not introduced for therapeutic reasons (thus, fewer demand characteristics were evident). When such interventions are embedded into the regular curriculum they become a part of the school's ethos, and any effects gained from the intervention become more generalizable to the entire school.

Recent reports and reviews have also recommended the use of active comparison groups (Flook et al., 2010; Meiklejohn et al., 2012), which we included in the current study's design. In response to a recent meta-analysis of school-based self-regulation programs (including mindfulness-based programs; Diamond \& Lee, 2011), one critic (Mercer, 2011) pointed out that when control groups do not experience any new and exciting activity, improvements on some scales that occur for the treatment group cannot be attributed to mechanisms beyond nonspecific effects of novelty. In the Flook et al. (2010) study, for example, controls did quiet reading in a regular classroom, whereas meditators moved tables and chairs to prepare for the activity and were allowed to sit on special cushions. Not controlling for these additional environmental variables makes it difficult to ascertain the source of an intervention's effectiveness. The present study attempts to control for such effects by giving the control group an enjoyable, nondidactic, experiential, and novel activity matched to course content (i.e., building a life-size Egyptian sarcophagus).

The current study examines the effects of 6 weeks of classroom-based, teacher-taught mindfulness meditation instruction on Internalizing, Externalizing, and Attention Problems, and affect in sixth-grade school children, as compared to a matched, active control group. Other programs often integrate mindfulness techniques as one component of a multicomponent curriculum that includes things such as social and emotional learning, nutritional information, and health and safety information. Thus, although many of these programs have shown positive effects, it is difficult to disentangle which components contributed to observed benefits and whether mindfulness training had any effects on its own. In order to determine the effects of mindfulness practices alone, students in this study received mindfulness meditation training as the sole component, with no other additions.

We predicted that those in the meditating condition would show improvements on the Internalizing Problems scale relative to controls, due to greater reductions in anxiety- and depression-related symptoms, and would improve relative to controls on the Externalizing Problems scale, due to reduced problematic behavior and acting out. In addition, as mindfulness training has been shown to improve attention and executive function, we predicted greater decreases in the Attention Problems subscale of the YSR in meditators compared to control students. Regarding YSR items addressing suicidality, we hypothesized that as mindfulness training has been shown to reduce feelings of depression and stress, endorsement of such items would be lower in the meditation condition compared to the control condition following the intervention. Because higher scores on the mindfulness scale (CAMS-R) should indicate improvements on the mental traits that mindfulness meditation is expected to train (i.e., attention, present-focus, awareness, and acceptance), we expected that those in the meditation condition would show greater improvements than controls. In addition, in the same way that others have hypothesized that higher scores on the mindfulness scale would be linked to more flexible coping styles (Feldman, Hayes, Kumar, Greeson, \& Laurenceau, 2007), we also expected improvements on the CAMS-R to be correlated with reductions in clinical symptoms and affect disturbance. 


\section{Method}

\subsection{Participants}

All sixth-grade students from two consecutive years $(n=114)$ in an independent Quaker school in Providence, RI were eligible to participate in this study. A normative sample of 101 sixth-grade students (55 boys, 46 girls; $M$ age $=11.79$ years, $S D=0.41$ years) agreed to participate in a randomized, controlled study between October 2007 and April 2009 . For more information about study participants, see the Preliminary analyses section of the Results section. ${ }^{1}$ All participating students and their parents completed informed assent and consent, respectively. Consent materials informed both parents and children that a child's endorsement of items related to self- or other-directed harm would result in referral to the school psychologist.

\subsection{Instruments}

\subsubsection{Student acceptability}

Student acceptability of the meditation practices was assessed through student journals that were collected during the meditation program. These journals were completed only by students in the meditation condition. Following each meditation session, students were given 5 min to "write about your experience with the meditation today" on an index card. Cards were handed in to the teacher for review of the students' experiences, degree of understanding, obstacles, or questions.

Because the journal data are textual narratives, qualitative methodology is the most appropriate approach. Thus, journal entries were transcribed and analyzed in line with qualitative methodology standards (Fonteyn, Vettese, Lancaster, \& Bauer-Wu, 2008; Miles, Huberman, \& Saldana, 2014). Content analysis is a systematic and objective means of describing and quantifying phenomena, and may be either inductive or deductive (Elo \& Kyngas, 2008). Inductive content analysis, where categories are derived from the data without theory, is used if there is little former knowledge about a phenomenon, whereas deductive theory-driven analysis is used when clear hypotheses or categories are known from previous studies.

In a previous study, Finucane and Mercer (2006) defined acceptability of a mindfulness course along two dimensions: engagement and perceived benefits. Engagement refers to the students' level of willingness and ability to follow the teachers' instructions to do the practices and included statements related to accepting or actively engaging with the practice versus rejecting the practice (i.e. deliberately doing something else during practice time). Because emotional and attention problems are the most common complaints among youth (Doll, 1996) and therefore the selected outcomes of the study, we selected these two categories of experience to compose the dimension of perceived benefits.

Analysis of student journals was performed with the Qualitative Solutions and Research International NVivo software program (QSR International, 2002). The software conducts an automated text search query that is "seeded" with selected base words (e.g., "attention" and "anxiety") that generalize via an option called "coding spread" to include related words or phrases (including shared stems and synonyms). Words related to emotions (e.g., "calm," "anxiety," and "distress") and attention (e.g., "concentration" and "focus") were used as seeds, and those and related words were identified and categorized into an attention benefit or emotion benefit category for each entry. Results are presented as number of individuals reporting the target variable on at least one occasion.

\subsubsection{Clinical syndromes}

The Youth Self Report (YSR) was used to assess the presence of clinical and subclinical symptoms and measure general wellbeing. The YSR contains 112 questions on a variety of behavioral and emotional problems (Achenbach \& Rescorla, 2001). Each question has three response options: 0,1 , and 2, which correspond to not at all or never true, somewhat or sometimes true, and very or often true. The sum of raw scores, rather than T-scores, were used, as recommended by the YSR manual (Achenbach \& Rescorla, 2001). The YSR is divided into two primary subscales, Internalizing Problems and Externalizing Problems. The Internalizing Problems scale includes 31 items related to internal affective difficulties, such as anxiety and depression as well as somatic complaints like headaches and fatigue. The YSR Internalizing Problems subscale has strong convergent validity with other measures, including the Diagnostic and Statistical Manual of Mental Disorders, Fourth Edition (DSM-IV; American Psychiatric Association, 1994) Depressive Disorder criteria of the clinician-administered DSM-IV Checklist (Hudziak, 1998; $r=.59, p<.001)$ and both teacher and parent ratings of Internalizing Problems subscale of the Behavioral Assessment System for Children (BASC; Reynolds \& Kamphaus, 1992; $r=.75-.83, p<.001$; Achenbach \& Rescorla, 2001). Internal consistency reliability (Cronbach's $\alpha$ ) for the YSR Internalizing Problems subscale in the current sample was high both before $(\alpha=.84$ and .91$)$ and after the intervention ( $\alpha=.84$ and .93) for meditators and controls, respectively. The Externalizing Problems subscale includes 29 items related to problem behaviors or "acting out," such as lying, disobedience, substance use, and aggressive behavior. The YSR Externalizing Problems subscale has strong convergent validity with other measures, including DSM-IV Conduct Disorder criteria of the clinician-administered DSM-IV Checklist (Hudziak, 1998; $r=.62, p<.001$ ) and both teacher and parent ratings of Externalizing Problems on the BASC (Reynolds \& Kamphaus, 1992; $r=.74-.88, p<.001$; Achenbach \& Rescorla, 2001). Internal consistency reliability (Cronbach's $\alpha$ ) for the YSR Externalizing Problems subscale in the current sample was high both before $(\alpha=.86$ and .82$)$ and after the intervention $(\alpha=.84$ and .85$)$ for meditators and controls, respectively.

\footnotetext{
${ }^{1}$ Data on race/ethnicity and SES/free and reduced price lunches was not collected.
} 
The YSR Attention Problems subscale includes 7 items related to concentration (daydreaming), self-control (impulsivity) and school performance and learning. The YSR Attention Problems subscale has strong convergent validity with other measures, including both teacher and parent ratings of the Conners' Ratings Scales ADHD index (Conners, 1997a, b; $r=.77-.88, p<.001$ ) and the BASC Attention Problem scales (Reynolds \& Kamphaus, 1992; $r=.58-.82, p<.001$; Achenbach \& Rescorla, 2001). Cronbach's $\alpha$ for the Attention Problems subscale in the current sample was .72 and .70 before and .72 and .80 after the intervention for meditators and controls, respectively.

In addition to clinical syndrome scales, adequate psychological assessment must also screen for endorsement of certain, "critical items" that warrant further clinical attention (Weiner, Graham, \& Naglieri, 2003). On the YSR, questions related to self-injurious behavior and suicidal ideation "have been rated by clinicians as being critical items requiring special attention" (Achenbach \& Rescorla, 2001, p. 34). Large clinical trials in adults often use 1 to 2 suicide-related items that are embedded in a larger scale to assess suicidal ideations associated with drug treatment (Perroud, 2011; Perroud et al., 2009). For children and adolescents, studies typically use 1 to 2 suicide-related items from the YSR to create a suicidal ideation subscale (Dhossche, Ferdinand, van der Ende, Hofstra, \& Verhulst, 2002; Espelage \& Holt, 2013; Ivarsson, Gillberg, Arvidsson, \& Broberg, 2002; Lessard \& Moretti, 1998; Vander Stoep et al., 2011). Desseilles et al. (2012) found that using single suicide items from commonly employed depression scales was a valid method of assessing suicidality that correlated with both clinician ratings and actual suicide attempts. Similarly, Vander Stoep et al. (2011) used a single item from the YSR (\#91) in a large sample of sixth graders and found that it was correlated with depression symptomatology as well as future suicide attempts. In a recent study of 661 fifth to eighth graders (Espelage \& Holt, 2013) and in the current study, items 18 ("I deliberately try to hurt or kill myself") and 91 ("I think about killing myself") were combined to make a suicidal ideation/behavior critical item subscale. In a sample of 661 students, the correlation between these 2 variables was .61 (Espelage \& Holt, 2013). Because of the infrequency of endorsement in the current (smaller) sample, correlation calculations were not possible. Endorsement of either of these critical items at any timepoint resulted in immediate referral to the school psychologist.

\subsubsection{Affect}

As our sample was a nonclinical student group, we opted to include a highly sensitive, nonclinical measure of affect in order to identify changes in emotional health. A modified version of the Spielberger State-Trait Anxiety Inventory - Child version (STAI-C) was used to assess positive and negative affect (O'Neil, Spielberger, \& Hansen, 1969). The STAI-C has been used previously in clinical and nonclinical adolescent samples and is one of the most frequently used instruments in pediatric research (Foster \& Park, 2012). Although the STAI was originally intended to assess anxiety, it is now considered to assess a broad range of emotional states (Bieling, Antony, \& Swinson, 1998; Caci, Bayle, Dossios, Robert, \& Boyer, 2003; Gros, Antony, Simms, \& McCabe, 2007). Similar to the Positive and Negative Affect Scale (Watson, Clark, \& Tellegen, 1988), the STAI-C is a 20-item self-report scale that assesses a respondent's emotional state by rating the presence of negative states ("worried" and "frightened") and positive states ("happy" and "satisfied"; O'Neil et al., 1969). The original child version of the STAI replaced the adult 4-point Likert scale with 3-choice options, very scared, scared, or not scared, but this format has been found to lack sensitivity to detect changes over time (Bringuier et al., 2009; Foster \& Park, 2012). Because visual analog scales of anxiety have been found to be more sensitive than forced choice scales (Foster \& Park, 2012) and to be associated with more reliability and validity evidence in children (Bringuier et al., 2009), the current study replaced the 3-choice format with a visual analog scale response format. Subjects mark a position on a horizontal line (i.e., from not scared to very scared or from not happy to very happy) on all 20 items; scores are measured in millimeters from the left side of the axis and range from 0 to 75. The standard STAI total scale is computed by summing all negative affect items and all reversed-scored positive affect items, and the total scale ranges from 0 to 1500 . Internal consistency reliability (Cronbach's $\alpha$ ) for the total score was high both before ( $\alpha=.92$ and .93) and after the intervention ( $\alpha=.93$ and .96) for meditators and controls respectively. A higher value on the total scale indicates more global affect disturbance, including high negative and low positive affect.

In addition to the STAI total scale targeting affective disturbance, we also employed a more narrowly focused variable to represent positive affect. The WHO's (1948) definition of health is "not merely the absence of disease or infirmity" but "a state of complete physical, mental and social well-being" (p. 100). Negative affect or psychopathology and positive emotions or wellbeing are functionally distinct (Ryff et al., 2006). Studies of mindfulness training in adults have found that it increases positive emotions (Anderson, Lau, Segal, \& Bishop, 2007; Nyklicek \& Kuijpers, 2008; Ortner et al., 2007), and changes in positive affect may be more sensitive to meditation effects in nonclinical samples (Roberts-Wolfe, Sacchet, Hastings, Roth, \& Britton, 2012). However, few studies have examined positive emotions in pre-adolescents, when affective disturbances begin to develop. Changes in positive emotions are particularly important because they are the earliest indicators of future depression, especially in nonclinical samples like the current sample (Wood \& Joseph, 2010). Thus, although the STAI total score reflects "affective disturbance," the total subscale does not provide information about the possible impact of mindfulness training on positive affect. Because of these factors, a 10-item exploratory Positive Affect subscale was created and computed by summing all positive affect items. Cronbach's $\alpha$ for the STAI Positive Affect subscale was .88 and .83 before and .89 and .92 after the intervention for meditators and controls, respectively.

\subsubsection{Mindfulness}

The Cognitive and Affective Mindfulness Scale (CAMS-R) is a 12-item measure that assesses subjective ability to regulate attention, maintain an awareness of present-moment experience, and maintain an accepting or nonjudgmental attitude toward present-moment experience (Feldman et al., 2007). For example, items include "I try to notice my feelings without judging them 
as bad or wrong." Participants rate how applicable each statement is to them using a 4-point Likert scale $(1=$ rarely/not at all to $4=$ almost always). Total scores on the scale range from 12 to 48 . The scale has demonstrated strong correlations to other measures of mindfulness, such as the Mindful Attention Awareness Scale (Brown \& Ryan, 2003), and has demonstrated construct validity evidence through positive associations with wellbeing and negative associations with rumination and worry (Feldman et al., 2007). The CAMS-R has been shown to have good reliability and validity in large heterogeneous student samples (Feldman et al., 2007) as well as in adolescents (Huppert \& Johnson, 2010). In adolescents who participated in a mindfulness intervention, CAMS-R scores were correlated with amount of mindfulness practice as well as resilience, wellbeing, and emotional stability (Huppert \& Johnson, 2010). In the current study, the CAMS-R had adequate internal consistency reliability before ( $\alpha=.77$ and .75 ) and after ( $\alpha=.80$ and .73) the intervention for both meditators and controls, respectively.

\subsection{Procedure}

Each year, in accordance with existing school policy, sixth-grade students were divided into four classrooms by a committee of educators who were familiar with the characteristics of each student. The committee was charged with creating four homologous classrooms in which there were symmetrical distributions of students by aptitude, learning style, maturity, social characteristics, and gender. Each fall, two classrooms were randomly assigned to the meditation intervention, while the remaining two classrooms were assigned to an active control condition. Randomization was performed by a simple coin flip. In each spring semester, condition assignment was reversed such that during the course of the sixth-grade year, all students received both the meditation curriculum and the active control curriculum. The current study only analyzed data from the fall semester across two years.

All study participants completed questionnaires before and after the 6-week intervention period. After consent, enrollment, and condition assignment, baseline data were collected from all students by research staff. Data were collected through a packet of questionnaires that were administered at school during regular hours. Researchers were blind to assignment at all time-points of data collection.

\subsubsection{Mindfulness training module}

The meditation condition in this study consisted of a meditation module lasting 6 weeks. The meditation condition was formulated according to Roth's (Roth, 2006, 2008, 2011, in press) Integrative Contemplative Pedagogy (ICP), which integrates traditional "third person" didactic, knowledge-based learning, with critical 1st person experiential learning. Third person learning refers to learning or gaining knowledge about a topic by reading books or receiving lectures from teachers or other experts. First person learning refers to learning that comes from the lived experience of the student. For example, in the ancient civilizations of Asia course, the didactic (3rd person) class content consisted of books and lectures about Asian civilizations, whereas the experiential (1st person) component consisted of actually experiencing three different meditation techniques: (1) breath awareness and breath counting; (2) awareness of thoughts, feelings, and sensations; and (3) body sweeps.

On each day during the 6-week trial, the history teacher led students in a short period of silent meditation at the beginning of the history class period. Initial meditation periods lasted only $3 \mathrm{~min}$, whereas the final meditation periods lasted as long as $12 \mathrm{~min}$. Before each meditation, students were asked to sit with a straight back in their desk chairs with their hands folded in their laps. Students were given a choice to sit with their eyes either open or closed during the meditation period. Breath awareness and breath counting were taught for the first 2 weeks, followed by 1 week each devoted to labeling of body sensations; labeling of thoughts, and emotions; and body sweeps. During the final 2 weeks, students were free to select from among the various techniques.

The instructions for the three techniques were as follows:

1. Breath awareness: "Practice paying attention to the tips of our noses or our abdomen. If your attention wanders, gently bring it back to either the tip of your nose or the abdomen. Feel the breath pass through your nose or feel the breath settle in your abdomen. Pay attention only to your breathing." Students were also instructed in a breath counting exercise to assist in the breath awareness practice: "Count your breaths in sets of five. Count each inhale/exhale combination as one breath. If you lose count, start again at one. It is not a competition or game to see how many you can count; use the counting as a way to focus on your breathing."

2. Awareness of thoughts, feelings, and sensations: "Label thoughts, feelings, and sensations. Thoughts are things in your mind, like, “I wonder if I did my history homework," or “do you think we'll have a pop quiz?” Feelings are things you feel in your body like hunger or boredom. Sensations are things you sense with your body, like an itch or a pain in your back. Once you've labeled your experience, stop paying attention to it and bring your focus back to your breathing."

3. Body sweeps: "Practice paying attention to different parts of your bodies by sweeping your attention through your bodies. I will give instructions throughout our sit to guide you through this practice." Students were then instructed to attend to sensations in their feet, legs, abdomen, chest, arms, and head, in successive order.

Following each daily meditation, students were instructed to record their reactions to the meditation in a practice journal. Journals were collected at the end of meditation sessions to serve as markers of responsiveness to the mindfulness training, for student acceptability analysis, as well as indicators of instructor fidelity to the schedule of practices.

Meditation instructions were delivered by the two regular history teachers according to Roth's ICP model. One teacher completed Roth's ICP (Roth, in press) training and had 5 years of prior daily meditation experience; the second teacher had no prior meditation experience but completed an 8-week Mindfulness-Based Stress Reduction (Kabat-Zinn, 1990) course provided 
by the research team prior to teaching. Each instructor followed identical practice instruction transcripts on the same schedule that was verified by weekly emails as well as corroborated with student journal entries.

\subsubsection{Active control condition}

The 3rd person (didactic) portion of the active control condition was a 6-week curriculum on ancient African History (including Egypt), taught by the same teacher that taught the meditation condition. To match the meditation condition's 1 st person component, the control condition included a nondidactic, experiential, and novel activity that was matched to the didactic content of the class: construction of a 3-dimensional life-sized model of a Pharaoh's tomb.

\subsection{Data analysis}

\subsubsection{Preliminary analysis}

Prior to analysis, all variables were examined for normality and no outliers were found (Cohen, 2001). Preliminary analyses were used to describe baseline characteristics and participant flow and adherence and to investigate any baseline group differences that might affect the main analyses.

\subsubsection{Main analysis}

The main analyses investigated the effect of the intervention on clinical syndromes, affect, and mindfulness. We conducted separate 2-way repeated measures ANOVAs for each variable to examine changes from baseline to posttreatment. Variables consisted of clinical syndromes (YSR Internalizing Problems, Externalizing Problems, and Attention Problems), affect (Total Affect Disturbance and Positive Affect) and mindfulness (CAMS-R total score). The between-subjects variable was a 2-level group variable, meditation (MED) or active control course (CON). The frequency of suicidal ideation or self-harm before and after meditation and control conditions was assessed with a likelihood ratio test (Zar, 1999). Nonsignificant Group-by-Time by teacher interactions for all outcome variables indicated that Group-by-Time interactions did not vary by teacher $(p>.05)$; therefore, we did not adjust for differential teacher effects in the current analyses. A more in-depth investigation of teacher effects is described elsewhere (Britton, in preparation).

\subsubsection{Correlation analysis}

Pearson product-moment correlation coefficients were used to assess whether changes in mindfulness were associated with improvements in affect and clinical syndromes. Meditators and controls were analyzed separately, to determine whether correlations between variables were related to the intervention or to general trait associations.

Data were analyzed using SPSS 19.0 software. Statistical significance was set at alpha levels $<.05$ using a two-tailed test. Effect sizes are reported as Cohen's $d$ and interpreted in the following manner: small $=0.20$, medium $=0.50$, and large $=0.80$ (Cohen, 2001). Because current statistical reporting guidelines (Cumming, 2014; Kline, 2013; Moher et al., 2010; Wilkinson \& APA Task Force for Statistical Inference, 1999) recommend interpreting results according to effect size and not statistical significance testing or dichotomous $p$-value cut-offs, nonsignificant $(p \geq .05)$ differences with an effect size of $d>.20$ are interpreted and discussed as meaningful.

\section{Results}

\subsection{Preliminary analyses}

Of the 114 eligible parent-student pairs, 101 (88.5\%) agreed to participate in the study. One subject (meditator) failed to attend baseline testing and was excluded from analysis. All other enrolled participants completed the intervention and exit testing, leaving an analyzed sample of 100 students (52 meditators and 48 controls), or $87.7 \%$ of eligible students in the grade over 2 years. Data were missing for one subject for the STAI and YSR at endpoint. In order to follow CONSORT recommendations for intent-to-treat rather than per protocol analyses (Schulz, Altman, \& Moher, 2010), missing data for this questionnaire were imputed using Last Observation Carried Forward analysis, which has been held to be valid when analyzing two treatment groups of equal size, as in the current study (Shao \& Zhong, 2003). There were no statistically significant differences $(p>.05)$ between meditating and control groups at baseline for age or gender or for any outcome measures (for baseline outcome measures, refer to Table 1).

\subsection{Student acceptability}

Students in the meditation condition produced a total of 633 journal entries about their experience with meditation, with an average of 12.2 entries per student and 25.8 words per entry. Based on the coding of qualitative feedback from students, the results regarding engagement and perceived benefits were as follows.

\subsubsection{Engagement}

The majority of students (94\%) reported engaging with the practice on nearly every occasion, whereas a small minority of students (6\%) rejected the practice at least once. One student reported rejecting the practice to intentionally daydream, and two 
Table 1

Time and group interaction effects.

\begin{tabular}{|c|c|c|c|c|c|c|c|c|c|}
\hline \multirow[t]{2}{*}{ Measure } & \multirow[t]{2}{*}{ Treatment } & \multicolumn{2}{|c|}{ Baseline } & \multicolumn{2}{|c|}{ Posttreatment } & \multicolumn{2}{|c|}{ Time ANOVA } & \multicolumn{2}{|c|}{$\begin{array}{l}\text { Group } \times \text { Time } \\
\text { ANOVA }\end{array}$} \\
\hline & & $M$ & $S D$ & $M$ & $S D$ & $F$ & $d$ & $F$ & $d$ \\
\hline \multirow[t]{2}{*}{ STAI total affect disturbance } & MED & 453.9 & 222.6 & 355.7 & 231.4 & $10.0^{* *}$ & 0.63 & 4.0\# & 0.41 \\
\hline & CON & 425.9 & 255.0 & 403.3 & 292.9 & & & & \\
\hline \multirow[t]{2}{*}{ STAI positive affect } & MED & 491.2 & 117.8 & 551.7 & 123.1 & $15.3^{* * *}$ & 0.81 & 3.8\# & 0.41 \\
\hline & $\mathrm{CON}$ & 508.0 & 123.1 & 528.1 & 139.6 & & & & \\
\hline \multirow[t]{2}{*}{ YSR Internalizing Problems } & MED & 12.5 & 7.1 & 10.4 & 6.6 & $24.1^{* * *}$ & 1.00 & 0.7 & 0.20 \\
\hline & $\mathrm{CON}$ & 13.7 & 10.1 & 10.6 & 10.1 & & & & \\
\hline \multirow[t]{2}{*}{ YSR Externalizing Problems } & MED & 8.4 & 5.8 & 6.9 & 5.2 & $15.4^{* * *}$ & 0.81 & 0.5 & 0.20 \\
\hline & $\mathrm{CON}$ & 8.1 & 6.1 & 7.0 & 5.6 & & & & \\
\hline \multirow[t]{2}{*}{ YSR Attention Problems } & MED & 4.7 & 2.7 & 3.8 & 2.6 & $19.0^{* * *}$ & 0.87 & 0.7 & 0.20 \\
\hline & $\mathrm{CON}$ & 4.1 & 2.5 & 3.5 & 2.8 & & & & \\
\hline \multirow[t]{2}{*}{ CAMS-R total } & MED & 33.0 & 5.6 & 33.0 & 6.1 & 0.10 & 0.00 & 0.1 & 0.00 \\
\hline & $\mathrm{CON}$ & 32.9 & 5.7 & 32.6 & 5.5 & & & & \\
\hline
\end{tabular}

Note. ANOVA = analysis of variance; MED = meditators; CON = controls; SD = standard deviation; STAI = Spielberger State-Trait Anxiety Inventory; YSR $=$ Youth Self Report; CAMS-R = Cognitive and Affective Mindfulness Scale - Revised

${ }^{* * *} p<.001,{ }^{* *} p<.01,{ }^{*} p<.05$, and $\# p \geq .05$ and $d>.20$.

other students indicated non-engagement by reporting that they disrupted the class during the meditation session on at least one occasion. Seven students (13\%) reported "feeling bored" or that "the meditation was boring" on at least one occasion but continued to engage despite this evaluation.

\subsubsection{Perceived benefits}

Forty-eight students (92\%) reported a perceived benefit of the meditation practices in terms of either an increase in relaxation and decrease in anxiety or an increase in the ability to focus or concentrate. Forty-three students (82\%) reported feeling more focused, concentrated, or having less distraction after practicing meditation on at least one occasion. Forty-six students (88\%) reported feeling more relaxed and calm or a decrease in stress, anxiety, worry, or tension after practicing meditation on at least one occasion.

\subsection{Main analysis}

\subsubsection{Clinical syndromes}

The effects of meditation training or active control condition on clinical syndromes were as follows.

3.3.1.1. Time effects. A statistically significant time effect was found for the Internalizing Problems scale of the YSR, indicating that all subjects collapsed across both conditions decreased in these symptoms, $F(1,98)=24.1, p<.001$, with a large effect size, $d=1.00$. Similar statistically significant time effects were found for Externalizing Problems, $F(1.98)=15.4, p<.001, d=0.81$, and Attention Problems, $F(1,98)=19.0, p<.001, d=0.87$. Further analyses revealed that all measured scales showed significant decreases for both meditators (all $p<.01$ ) and controls (all $p<.05$ ) from baseline to postintervention, indicating large improvements in clinical symptoms in both groups over the 6-week period.

3.3.1.2. Group-by-Time interactions. Contrary to predictions of greater improvements in the mindfulness condition, two-way (Group-by-Time) interactions were not statistically significant for Internalizing Problems, $F(1,98)=0.7, p=.39, d=0.20$, Externalizing Problems $F(1,98)=.48, p=.49, d=0.20$, or Attention Problems, $F(1,98)=0.7, p=.40, d=0.20$, indicating that neither group improved more than the other.

\subsubsection{Suicidal ideation or self-harm}

In line with predictions, mindfulness produced greater reductions in the development of suicidality and self-harm than the control condition. At baseline, one student in each group (meditators and controls) reported suicidal ideation or self-harm. However, we found that control students were more likely than students in the meditation group to develop suicidal ideation or self-harm over the 6-week trial period. At postintervention, 5 controls ( $10.4 \%$ of controls) reported either suicidal ideation or self-harm, whereas no meditators reported such behavior or ideation. This difference was statistically significant (likelihood ratio $=7.73, p=.005$ ). All students who endorsed high-risk items were assessed immediately by the school psychologist to determine the need for additional evaluation, treatment, or continued monitoring.

\subsubsection{Affect}

The effects of mindfulness and active control conditions affect were as follow. 
3.3.3.1. Time effects. A significant time effect for both total affect disturbance, $F(1,98)=10.04, p=.002, d=0.63$, and positive affect, $F(1,98)=15.3, p<.001, d=0.81$, indicated a reduction in overall affect disturbance and an increase in positive affect and for all participants across the 6 -week trial period.

3.3.3.2. Group-by-Time interactions. Compared to controls, meditators showed greater reductions in total affect disturbance, with a small to medium effect size, although the difference was not statistically significant, $F(1,98)=3.95, p=.050, d=0.41$. Meditators showed greater increases in positive affect over the trial period as compared to controls, and although the difference was not statistically significant, $F(1,98)=3.82, p=.053, d=0.41$, the effect size indicates a valid relationship between mindfulness training and increased positive affect that is worthy of further investigation.

\subsubsection{Mindfulness}

No significant changes in self-reported mindfulness were found among any groups over time, $F(1,98)=0.1, p=.78, d=0.00$. The Group-by-Time interaction for mindfulness was not significant, $F(1,98)=.110, p=.74, d=0.00$, indicating that, contrary to hypotheses, mindfulness training did not increase scores on this mindfulness scale.

\subsection{Correlation analysis}

As predicted, improvements in CAMS-R total score among meditators were significantly correlated with reductions in overall affect disturbance $(r=-.44, p=.001)$ and with increases in positive affect $(r=.43, p=.002)$ as measured by the STAI. See Table 2. These correlations were not statistically significant within the control group $(r=.09, p>.05$ for positive affect and $r=.01$, $p>.05$ for total affect disturbance). In both meditators and controls, changes in mindfulness scores were not correlated significantly with any of the YSR measures.

\section{Discussion}

In an attempt to improve upon the methodological limitations of wait-list controlled, elective, school-based mindfulness intervention studies, the present study examined a curriculum-integrated, teacher-taught meditation intervention in comparison to an equally novel, engaging and experientially-based control in a randomized trial. As the field of school-based mindfulness interventions approaches the point of public policy and the implementation of meditation within schools becomes ever more common, this study offers a model of how such interventions might function, and how they might differ from other school-based interventions (e.g. afterschool electives). The study had several objectives: to assess feasibility and acceptability, to investigate whether mindfulness-meditation alone had any effects, and to compare the meditation program to an active control condition.

In terms of feasibility, the results of the present study suggest that incorporating a meditation intervention into a standard school curriculum is feasible to teachers and administrators and acceptable to students. According to student journals, the majority of students both engaged with the practice and reported perceived benefits. Educators informally reported that the meditation was easy to implement within the Asian history curriculum and that students were eager to learn new techniques and looked forward to the daily meditation period. Other teachers noted that students asked for brief meditation periods at the start of their classes, indicating the popularity of some of the meditative techniques. Administrators responded positively to the intervention, recommending its permanent inclusion in the school's history curriculum.

Comparing the mindfulness intervention to an equally engaging active control condition yielded mixed results. Both the meditation group and the active control group produced equally large decreases in clinical symptoms, such as Internalizing Problems, Externalizing Problems, and Attention Problems, with large effect sizes (all $d s>0.80$ ), but no difference in magnitude between groups. On measures of both total affect disturbance and positive affect, meditators showed greater improvements over controls with small to medium effect sizes ( $d s=.41$ ) that were not statistically significant ( $p=.05$ and $p=.053$, respectively). Interpretation of results based on dichotomous significance testing $p$-value cutoffs suggests that mindfulness training yields no benefit on affect beyond those produced by building an Egyptian sarcophagus. In contrast, interpretation based on effect size estimates indicates mindfulness training yields a small to medium effect size benefit in affect over the active control condition.

Table 2

Correlations between changes in outcomes and changes in mindfulness for meditators and controls.

\begin{tabular}{lcc}
\hline Correlation $(r)$ & MED & CON \\
\hline CAMS-R total & $-.46^{* *}$ & .01 \\
STAI total affect disturbance & $.37^{*}$ & .09 \\
STAI positive affect & -.22 & -.23 \\
YSR Internalizing Problems & .17 & -.03 \\
YSR Externalizing Problems & -.17 & -.23 \\
YSR Attention Problems &
\end{tabular}

Note. MED = meditators; CON = controls; CAMS-R = Cognitive and Affective Mindfulness Scale - Revised; STAI = Spielberger State-Trait Anxiety Inventory; YSR $=$ Youth Self Report.

** $p<.01$.

$* p<.05$. 
Whereas decreases in clinical symptoms did not differ by group, mindfulness training did show larger improvements than controls on measures of suicidal ideation. Children who were randomized to the meditation group had a reduced risk of developing suicidal ideation and thoughts of self-harm compared to the controls. With such a small sample, and limited follow-up, it is difficult to conclude that these effects were due to meditation. However, these preliminary results are encouraging, especially given the prevalence of both suicidal ideation and self-harm in adolescents. Suicidal ideation is relatively common in adolescents, even in nonclinical samples (Kloos, Collins, Weller, \& Weller, 2007). About 20\% of middle school children (Go \& Cupertino, 2001) and high school students (Field, Diego, \& Sanders, 2001) in the United States admit suicidal ideation, with similar estimates (16\% to 32\%) in other countries (Kirkcaldy, Eysenck, \& Siefen, 2004; Peltzer \& Pengpid, 2012) and varied endorsement depending on the wording of the question. Endorsement of "thoughts of killing oneself" in community samples has been estimated at $5 \%$ to $6 \%$ for sixth-grade students (Stoep, McCauley, Flynn, \& Stone, 2009) with an increase to $11.3 \%$ for eighth-grade students and $14.5 \%$ for twelfth-grade students (Pfeffer, 1997; Stoep et al., 2009).

Deliberate self-injury in adolescents is also not uncommon, with incidence estimates between $5 \%$ and $47 \%$ of the general adolescent population and between $20 \%$ and $60 \%$ of clinical adolescent populations (Favazza, 1998; Laye-Gindhu \& Schonert-Reichl, 2005; Lloyd-Richardson, Perrine, Dierker, \& Kelley, 2007; Nock \& Prinstein, 2005; Ross \& Heath, 2002). For middle schoolers, approximately 7.5\% admit self-injury (Hilt, Nock, Lloyd-Richardson, \& Prinstein, 2008), with typical age of onset starting around 12 years (Rodham \& Hawton, 2009), the age of the current sample. Thus, the incidence of suicidal ideation and self-harm in our sixth grade sample is comparable to other nonclinical samples, which highlights the need for both increased monitoring and intervention in this age group (Pfeffer, 2001).

Students in both groups displayed large improvements on each of the three clinical symptom subscales measured, as well as affective measures, suggesting that whereas the meditation instruction produced observable cognitive and affective benefits, these benefits were mirrored by similar improvements among those in the active control history class. Several explanations for this concurrent improvement are possible. First, as both courses involved novel, nondidactic classroom activities, it is possible that considerable benefits in attention and affect can be produced by a wide range of engaging, experiential activities that are not limited to meditation. For example, Pinniger, Brown, Thorsteinsson, and McKinley (2012) found that tango dancing was equally beneficial as mindfulness training for depression, and more beneficial for stress. Second, because the teachers who taught the meditations also instructed the control groups, and the effect of teachers' own contemplative practices can influence their moods and prosocial behaviors (Kemeny et al., 2012), it is possible that the benefits shown by all participants may be due to shared exposure to a contemplative teacher. Indeed, evidence from the field of contemplative education suggests that intervening with teachers, instead of directly with students, may be an equally or more effective method for yielding desired behavioral outcomes in students, in addition to making teaching more engaging and effective for teachers (Jennings \& Greenberg, 2009; Roeser, Skinner, Beers, \& Jennings, 2012). Third, with only three response options (0,1, and 2), the YSR may be less sensitive to change than the STAI-C, which detected nonsignificant $(p=.05)$ Group-by-Time effects with a small to medium effect size $(d=.41)$. Finally, it is also possible that the nonclinical severity of symptoms at baseline could have contributed to fewer group differences on clinical symptom scales.

Although there were no group differences in measures of mindfulness, improvements on the STAI were associated with increases in self-reported mindfulness scores in meditators but not controls, which offers partial support of our proof of concept: that "mindfulness" is what mediates improvements. Neither meditators nor controls showed significant changes on the subjective mindfulness measure over the intervention period. At present, however, researchers have questioned the validity of self-reported mindfulness measures because the ability to report on one's level of awareness requires self-awareness itself, thus self-reporting on mindfulness becomes inherently problematic (Grossman \& Van Dam, 2011; Van Dam, Earleywine, \& Borders, 2010; Van Dam, Hobkirk, Danoff-Burg, \& Earleywine, 2012). In addition, it may be that the small dosage of meditation was insufficient to generate group-level effects. For example, Huppert and Johnson (2010) found only trend level changes on self-reported mindfulness (CAMS-R) after mindfulness training for the whole group but greater increases in CAMS-R scores in adolescents who practiced more. Although our sample scored in a similar range on the CAMS-R as Huppert and Johnson (2010) sample, it is possible that the lack of change on this measure was due to our sample's prior exposure to the contemplative environment of a Quaker school (e.g., silent Quaker meetings).

\subsection{Strengths, limitations, and recommendations for future research}

The study included strengths as well as limitations. In terms of strengths, this study is a randomized control trial with an active control group, and as such represents one of the few rigorous trials of a school-based mindfulness program in a field that is plagued by poor quality research (Greenberg \& Harris, 2012). In addition, this study is one of the few to isolate the effects of mindfulness meditation practice, independent of other components that are often included in mindfulness-based interventions, such as social interaction/dyads, yoga, or other skills training. Similarly, this study is one of the few to compare mindfulness with an equally novel and engaging active control condition, rather than a passive no-treatment condition or waitlist. Together, these design choices help address the question of how much of the benefits reported by previous school-based mindfulness interventions is due to actual mindfulness meditation and how much is due to non-specific effects. In addition, because the meditation intervention was integrated into a standard classroom curriculum that was required for all students and taught by the regular teacher, this study may reduce the self-selection bias and threats to external validity that are present in studies of after-school or pull out programs that are taught by specialists. The fact that the same teacher taught both meditation and control conditions controls for teacher personality effects across conditions, which also helps isolate the effects of the meditation practice. Although the study has many 
strengths, it also has many limitations that should be considered when interpreting the findings and when designing future studies.

\subsubsection{Measurement limitations}

The measures in the current study have several limitations. First and more generally, all measures were self-report which are subject to demand characteristic and expectancy effects. Future studies are encouraged to employ additional behavior observations by teachers and parents and objective laboratory measures. Second, it should also be noted that we modified the response format of the STAI from a Likert to a visual analog scale, which may have increased its ability to detect small Group-by-Time differences, but also presents challenges to its validity and generalizability (McCormack, Horne, \& Sheather, 1988; Wewers \& Lowe, 1990). Similarly, our exploratory Positive Affect subscale can only suggest that mindfulness-related changes in positive affect should be investigated with validated scales in future studies. We also recommend that future studies employ measures of wellbeing that purposefully assess the full range of functioning (i.e., global life satisfaction). Third, our measure of suicidal ideation and behavior only consisted of 2 items that were extracted from a larger scale, which raises questions of reliability and validity. Although this method is a commonly used and valid method of assessing suicidality (Desseilles et al., 2012; Dhossche et al., 2002; Espelage \& Holt, 2013; Ivarsson et al., 2002; Lessard \& Moretti, 1998; Vander Stoep et al., 2011), future studies should use scales that are specifically designed to assess suicidality. Fourth, our assessment of student acceptability used qualitative methods that, although valid (Elo \& Kyngas, 2008), could be measured more systematically with quantitative measures. Similarly, school feasibility and the attitudes of educations, administrators and parents were measured informally and should also be systematically assessed with questionnaires. Future studies should be careful to employ sensitive measures that can detect small changes over a short period of time and assess the full range of functioning, including both suicidal ideation and self harm and wellbeing and flourishing. Self-report measures should be triangulated with objective neuropsychological measures (Baijal, Jha, Kiyonaga, Singh, \& Srinivasan, 2011; van de Weijer-Bergsma, Formsma, de Bruin, \& Bogels, 2012) and observational raters who are blind to treatment allocation (Carboni et al., 2013).

\subsubsection{Sample selection limitations}

The current study has many limitations related to the sample. The study was conducted in a Quaker school, and although we did not assess race, ethnicity, or socioeconomic status, there is likely an overrepresentation of high-income, Caucasian families in our sample than the general population. Little can be surmised about the generalizability of these results for students outside of Quaker contexts; it may be that such students benefit more from mindfulness interventions because they are more comfortable with contemplative practices, given the regularity of silent meetings at Quaker schools. Similarly, the teachers and administrators appeared in support of the meditation program, but this appearance may be an artifact of a Quaker school orientation. Alternatively, Quaker students may actually benefit less than non-Quaker students from a mindfulness intervention, given that such meetings may already serve the purpose of cultivating the skills associated with mindfulness. To determine these intervention effects, further intervention research is needed to compare the effectiveness of interventions between students from schools with differing school philosophies and cultural practices.

An important question that future studies should be investigating is whether mindfulness or meditation training is equally beneficial for everyone or whether some individuals may be better off with other approaches. Indeed, studies in adults have found that pre-existing characteristics predict treatment outcome (Cordon, Brown, \& Gibson, 2009) and that mindfulness or meditation-based interventions may be maximally effective (Arch \& Ayers, 2013; Ma \& Teasdale, 2004; Teasdale et al., 2000), ineffective (Jazaieri, Goldin, Werner, Ziv, \& Gross, 2012; Mularski et al., 2009), or even contraindicated for certain types of people (Arch \& Ayers, 2013; Ma \& Teasdale, 2004). Although some clinical studies in children share the same self-selection bias as adult studies, many school-based programs are implemented at the institutional level so that all students receive meditation as part of school and not by individual elective (Metz et al., 2013). In this context, the question of individual differences in response to meditation is even more important. So far, the effects of mindfulness-based training programs in children and adolescents have been found to be effected by pre-existing characteristics, including baseline levels of executive function (Flook et al., 2010), developmental age (Schonert-Reichl \& Lawlor, 2010), family environment (Barnes, Gregoski, Tingen, \& Treiber, 2010), and gene by environment interactions (Gregoski et al., 2012), such that some children benefit more than others and some do not benefit. Thus, it has been recommended that "researchers need to be cognizant of the possibility of iatrogenic effects that certain practices could have with children of different ages and characteristics" (Greenberg \& Harris, 2012, p. 164). Future studies should be sure to assess race, ethnicity and socioeconomic status, and free/reduced price lunch status.

\subsubsection{Intervention-related limitations and suggestions}

The current study has several limitations related to the interventions, including treatment fidelity, parallel changes in both groups, dosage considerations, and teacher qualities.

4.1.3.1. Treatment fidelity. Although we tried to carefully match the mindfulness and active control conditions for comparability, we did not formally assess the fidelity of the teacher to adhere to either protocol and, therefore, cannot be sure that the students received the conditions we planned. Although the teachers' course curriculum plans and the students' meditation journals give some indication that the meditation protocol was followed, future studies should assess treatment fidelity of all conditions in a much more rigorous and formal manner. Similarly, only students in the meditation condition completed journals about their experience, which not only leaves the experience of the control students unexamined but also introduces the possibility that any 
changes or benefits produced in the meditation condition were due to journal writing rather than meditating. Future studies should exercise even more rigor in ensuring comparability between comparison conditions in order to make valid conclusions.

4.1.3.2. Parallel changes in both groups. Although the results of this study suggest that mindfulness training may yield specific benefits beyond the control condition for suicidality and possibly affect, mindfulness training yielded largely equal benefits on clinical symptoms as building a tomb. There are many possible reasons why mindfulness training did not yield stronger benefits over the control. One possibility is low levels of clinical symptoms at baseline, leading to a floor effect, although this would not explain why both conditions produced large, statistically significant improvements. Detecting differences between two active treatments requires larger sample sizes than comparing to a passive or waitlist control because the anticipated differences are smaller. Indeed, the study was powered to detect medium to large between group differences but was underpowered to detect smaller differences, which may explain why the differences in affect had meaningful effect sizes but were not statistically significant.

Another potential cause of group parity is that the isolation of mindfulness meditation (excluding dyads, yoga, or other exercises) and the brevity of the intervention and the short duration of daily meditations may have reduced the effectiveness of the intervention. The high quality of the control group's alternate activity (e.g., versus the absence of activities in a waitlist control design) also contributed to the lack of difference between conditions. The lack of difference between conditions may be interpreted in several ways. As described above, both conditions produced large benefits on multiple measures, which may indicate that many novel activities in school, including mindfulness meditation, are beneficial for children's mental health. Similarly, a recent meta-analysis of meditation programs versus active controls concluded that there was "no evidence that meditation programs were better than any active treatment" (Goyal et al., 2014, p. 357). However, even if the pretest-to-posttest comparisons show gains, sizeable effects, and significant differences from baseline, we cannot rule out maturation, simple passage of time, or repeated assessment as the potential "causes" of the differences. Following this reasoning, we cannot infer global potential beneficial effects of the meditation intervention (or the comparison intervention).

4.1.3.3. Dosage. The ideal meditation "dosage" for children and adolescents is still unknown. Students in the present study meditated for approximately 5 to $10 \mathrm{~min}$ a day for 4 to 5 days a week. This amount of meditation time is limited as compared to that of clinical mindfulness interventions for adults, which commonly involve as much as 45 min of practice a day (Segal, Teasdale, \& Williams, 2002; Teasdale et al., 2000) and other homework exercises. Some adolescent interventions have demonstrated effects with 20 or more minutes of daily practice (Biegel et al., 2009; Saltzman \& Goldin, 2008), yet other studies have recorded significant effects of meditation in children and adolescents with as little as 5 to 10 min of daily meditation (Britton et al., 2010; Fernando \& Keller, 2012; Saltzman \& Goldin, 2008; Zylowska et al., 2008). Although the present study involved a single daily meditation period, at least one other study has incorporated a thrice-daily meditation intervention (Schonert-Reichl \& Lawlor, 2010). The intervention in question is notable because of the ease with which it was integrated into a sixth-grade history course. Further research should examine the impact of increased meditation time, especially the efficacy of mandated "homework" mindfulness practice. In the present study, although students were not instructed to practice outside of class, anecdotal evidence suggests that some of them elected to meditate in their free time. Thus, dosage may have varied significantly between students, and total time meditating may be related to emotional changes.

Although we found a decreased risk for developing suicidal ideation within the mindfulness meditation group, the present intervention was only delivered over a 6 -week period. A longer follow-up period and longitudinal data with a larger sample would be helpful in determining whether mindfulness training is capable of providing long-term protection against serious mental illness and suicidal ideation. In addition, because all children that endorsed high-risk items were referred to the school psychologist, the impact of external treatment on study outcomes is unknown.

4.1.3.4. Teachers. Two different teachers participated in the study and served as their own controls by teaching both meditation and control conditions. Although this design controls for teacher or personality effects across conditions, this design does not control for difference in instructor enthusiasm. Ideally the control instructor would believe as strongly in the efficacy of the control condition (MacCoon et al., 2012). Although each one served as their own control, they had different levels of prior training in mindfulness and may have differed in the quality of their delivery or impact on children. On one hand, this range of training is representative of school-based mindfulness programs, but training warrants further investigation, which is beyond the scope of this article and covered elsewhere (Britton, in preparation; Jennings \& Greenberg, 2009; Singh, Lancioni, Winton, Karazsia, \& Singh, 2013). The impact of different levels of instructor mindfulness practice or training may begin to answer the minimal training prerequisites to serve as successful interventionists (Britton, in preparation; Jennings, Frank, Snowberg, Coccia, \& Greenberg, 2013; Jennings \& Greenberg, 2009).

\subsection{Conclusion}

The current enthusiasm and implementation of school-based mindfulness or meditation programs have outpaced the empirical support for the efficacy of the programs. High-quality randomized control trials are few. In the present study, sixth-grade children were randomized into a mindfulness meditation training compared to an equally novel and engaging active control condition as part of standard, mandatory middle school course curriculum. Although both conditions showed large improvements in Internalizing Problems, Externalizing Problems, Attention Problems, and affect, students in the mindfulness meditation condition showed reduced 
risk of developing suicidal ideation and self-harming thoughts and behaviors. These results suggest that mindfulness training may yield both unique and nonspecific effects that are shared by other novel activities. Further research with a larger sample is recommended to ascertain whether the observed effects can be replicated and to determine the extent to which meditation can produce long-term prophylactic effects.

\section{Acknowledgments}

Funding for this research was provided by grants T32-AT001287, MH067553-05, and K23-AT006328-01A1 from the National Institutes of Health, the Mind and Life Institute, the Lenz Foundation, the Hershey Foundation, and the Brown University Contemplative Studies Initiative. We would also like to thank the Clinical and Affective Neuroscience Laboratory and the Moses Brown School for their help and collaboration.

\section{References}

Achenbach, T., \& Rescorla, L. (2001). Manual for ASEBA school-age forms and profiles: Youth Self Report. Burlington VT: University of Vermont, Research Center for Children, Youth, \& Families.

American Psychiatric Association (1994). Diagnostic and Statistical Manual of Mental Disorders. (4th ed.). Washington, DC: Author.

Anderson, N., Lau, M., Segal, Z., \& Bishop, S. (2007). Mindfulness-based stress reduction and attentional control. Clinical Psychology and Psychotherapy, 14, 449-463.

Arch, J., \& Ayers, C. R. (2013). Which treatment worked better for whom? Moderators of group cognitive behavioral therapy versus adapted mindfulness based stress reduction for anxiety disorders. Behaviour Research and Therapy, 51, 434-442.

Baijal, S., Jha, A. P., Kiyonaga, A., Singh, R., \& Srinivasan, N. (2011). The influence of concentrative meditation training on the development of attention networks during early adolescence. Frontiers in Psychology, 2, 153, http://dx.doi.org/10.3389/fpsyg.2011.00153.

Barnes, V. A., Gregoski, M. J., Tingen, M. S., \& Treiber, F. A. (2010). Influences of family environment and meditation efficacy on hemodynamic function among African American adolescents. Journal of Complementary and Integrative Medicine, 7.

Beauchemin, J., Hutchins, T., \& Patterson, F. (2008). Mindfulness meditation may lessen anxiety, promote social skills, and improve academic performance among adolescents with learning disabilities. Complementary Health Practice Review, 13, 34-45.

Beautrais, A. L. (2003). Suicide and serious suicide attempts in youth: A multiple-group comparison study. American Journal of Psychiatry, 160, 1093-1099.

Biegel, G., Brown, K., \& Shapiro, S. (2009). Mindfulness-based stress reduction for the treatment of adolescent psychiatric outpatients: A randomized clinical trial. Journal of Consulting and Clinical Psychology, 77, 855-866.

Bieling, P. J., Antony, M. M., \& Swinson, R. P. (1998). The State-Trait Anxiety Inventory, Trait version: Structure and content re-examined. Behaviour Research and Therapy, 36, 777-788.

Birdee, S. S., Yeh, G. Y., Wayne, P. M., Phillips, R. S., Davis, R. B., \& Gardiner, P. (2009). Clinical applications of yoga for the pediatric population: A systematic review. Academic Pediatrics, 9, 212-220.

Black, D. S., Milam, J., \& Sussman, S. (2009). Sitting-meditation interventions among youth: A review of treatment efficacy. Pediatrics, $124,532-541$.

Blair, C., \& Peters, R. (2003). Physiological and neurocognitive correlates of adaptive behavior in preschool among children in head start. Developmental Neuropsychology, 24, 479-497, http://dx.doi.org/10.1207/S15326942DN2401_04.

Blair, C., \& Razza, R. P. (2007). Relating effortful control, executive function, and false belief understanding to emerging math and literacy ability in kindergarten. Child Development, 78, 647-663, http://dx.doi.org/10.1111/j.1467-8624.2007.01019.x.

Bloom, B., Dey, A. N., \& Freeman, G. (2006). Summary health statistics for U.S. children: National Health Interview Survey, 2005. Vital Health Statistics, 10, 1-84.

Bogels, S., Hoogstad, B., van Dun, L., De Shutter, S., \& Restifo, K. (2008). Mindfulness training for adolescents with externalising disorders and their parents. Behavioural and Cognitive Psychotherapy, 36, 193-209.

Bringuier, S., Dadure, C., Raux, O., Dubois, A., Picot, M. C., \& Capdevila, X. (2009). The perioperative validity of the visual analog anxiety scale in children: A discriminant and useful instrument in routine clinical practice to optimize postoperative pain management. Anesthesia \& Analgesia, 109, 737-744, http://dx. doi.org/10.1213/ane.0b013e3181af00e4.

Britton, W. (2014n). The impact of teacher characteristics on school-based mindfulness outcomes. (in preparation).

Britton, W. B., Bootzin, R. R., Cousins, J. C., Hasler, B. P., Peck, T., \& Shapiro, S. L. (2010). The contribution of mindfulness practice to a multicomponent behavioral sleep intervention following substance abuse treatment in adolescents: A treatment-development study. Substance Abuse, 31, 86-97, http://dx.doi.org/10. $1080 / 08897071003641297$.

Broman, C. L. (2012). Race differences in the receipt of mental health services among young adults. Psychological Services, 9, 38-48, http://dx.doi.org/10.1037/ a0027089.

Brown, K. W., \& Ryan, R. M. (2003). The benefits of being present: The role of mindfulness in psychological well-being. Journal of Personality and Social Psychology, $84,822-848$.

Burke, C. (2010). Mindfulness-based approaches with children and adolescents: A preliminary review of current research in an emergent field. Journal of Child and Family Studies, 19, 133-144.

Burns, B., Costello, E., Angold, A., Tweed, D., Stangl, D., \& Farmer, E. (1995). Children's mental health service use across service sectors. Health Affairs, 14, 149-159.

Caci, H., Bayle, F. J., Dossios, C., Robert, P., \& Boyer, P. (2003). The Spielberger Trait Anxiety Inventory measures more than anxiety. European Psychiatry, 18, 394-400.

Carboni, J. A., Roach, A. T., \& Fredrick, L. D. (2013). Impact of mindfulness training on the behavior of elementary students with attention-deficit/hyperactive disorder. Research in Human Development, 10, 234-251.

Carlson, S. M., Mandell, D. J., \& Williams, L. (2004). Executive function and theory of mind: Stability and prediction from ages 2 to 3. Developmental Psychology, 40, 1105-1122, http://dx.doi.org/10.1037/0012-1649.40.6.1105.

Carlson, S. M., \& Moses, L. J. (2001). Individual differences in inhibitory control and children's theory of mind. Child Development, 72, $1032-1053$.

Chambers, R., Lo, B., \& Allen, N. B. (2008). The impact of intensive mindfulness training on attentional control, cognitive style and affect. Cognitive Research and Therapy, 32, 303-322.

Cohen, B. (2001). Explaining psychological statistics. New York, NY: Wiley.

Conners, C. K. (1997a). Conners' Parent Rating Scale-Revised. North Tonawanda, NY: Multi-Health Systems.

Conners, C. K. (1997b). Conners' Teachers Rating Scale-Revised. North Tonawanda, NY: Multi-Health Systems.

Cordon, S., Brown, K., \& Gibson, P. (2009). The role of mindfulness-based stress reduction on perceived stress: Preliminary evidence for the moderating role of attachment style. Journal of Cognitive Psychotherapy, 23, 258-269.

Costello, E., Angold, A., \& Keeler, G. (1999). Adolescent outcomes of childhood disorders: The consequences of severity and impairment. Journal of the American Academy of Child and Adolescent Psychiatry, 38, 121-128.

Costello, E. J., Egger, H., \& Angold, A. (2005). 10-Year research update review: The epidemiology of child and adolescent psychiatric disorders: I. Methods and public health burden. Journal of the American Academy of Child and Adolescent Psychiatry, 44, 972-986, http://dx.doi.org/10.1097/01.chi.0000172552.41596.6f.

Cumming, G. (2014). The new statistics: Why and how. Psychological Science, 25, 7-29, http://dx.doi.org/10.1177/0956797613504966.

Davidson, R. J., \& McEwen, B. S. (2012). Social influences on neuroplasticity: Stress and interventions to promote well-being. Nature Neuroscience, 15, 689-695, http://dx.doi.org/10.1038/nn.3093. 
DeRigne, L. (2010). What are the parent-reported reasons for unmet mental health needs in children? Health \& Social Work, 35, 7-15.

Desseilles, M., Perroud, N., Guillaume, S., Jaussent, I., Genty, C., Malafosse, A., et al. (2012). Is it valid to measure suicidal ideation by depression rating scales? Journal of Affective Disorders, 136, 398-404, http://dx.doi.org/10.1016/j.jad.2011.11.013.

Dhossche, D., Ferdinand, R., van der Ende, J., Hofstra, M. B., \& Verhulst, F. (2002). Diagnostic outcome of adolescent self-reported suicidal ideation at 8-year followup. Journal of Affective Disorders, 72, 273-279.

Diamond, A., \& Lee, K. (2011). Interventions shown to aid executive function development in children 4 to 12 years old. Science, 333, 959-964, http://dx.doi.org/ $10.1126 /$ science.1204529.

Doll, B. (1996). Prevalence of psychiatric disorders in children and youth: An agenda for advocacy by school psychology. School Psychology Quarterly, 11, 20-47.

Elo, S., \& Kyngas, H. (2008). The qualitative content analysis process. Journal of Advanced Nursing, 62, 107-115.

Espelage, D. L., \& Holt, M. K. (2013). Suicidal ideation and school bullying experiences after controlling for depression and delinquency. Journal of Adolescent Health, 53, S27-S31, http://dx.doi.org/10.1016/j.jadohealth.2012.09.017.

Favazza, A. R. (1998). The coming of age of self-mutilation. Journal of Nervous and Mental Disease, 186, 259-268.

Feldman, G., Hayes, A., Kumar, S., Greeson, J., \& Laurenceau, J. -P. (2007). Mindfulness and emotion regulation: The development and initial validation of the Cognitive and Affective Mindfulness Scale-Revised (CAMS-R). Journal of Psychopathology and Behavioral Assessment, 29, 177-190.

Fernando, R., \& Keller, S. (2012). Measuring the efficacy and sustainability of the mindful schools mindfulness-based in-class intervention. Paper presented at the 10th Annual International Scientific Conference: Investigating and integrating mindfulness in medicine, health care, and society. MA: Norwood.

Field, T., Diego, M., \& Sanders, C. E. (2001). Adolescent suicidal ideation. Adolescence, 36, 241-248.

Finucane, A., \& Mercer, S. W. (2006). An exploratory mixed methods study of the acceptability and effectiveness of mindfulness-based cognitive therapy for patients with active depression and anxiety in primary care. BMC Psychiatry, 6, 14, http://dx.doi.org/10.1186/1471-244X-6-14.

Flisher, A. J., Kramer, R. A., Grosser, R. C., Alegria, M., Bird, H. R., Bourdon, K. H., et al. (1997). Correlates of unmet need for mental health services by children and adolescents. Psychological Medicine, 27, 1145-1154, http://dx.doi.org/10.1017/S0033291797005412.

Flook, L., Smalley, S. L., Kitil, M. J., Galla, B. M., Kaiser-Greenland, S., Locke, J., et al. (2010). Effects of mindful awareness practices on executive functions in elementary school children. Journal of Applied School Psychology, 26, 70-95, http://dx.doi.org/10.1080/15377900903379125.

Fonteyn, M. E., Vettese, M., Lancaster, D. R., \& Bauer-Wu, S. (2008). Developing a codebook to guide content analysis of expressive writing transcripts. Applied Nursing Research, 21, 65-168.

Foret, M. M., Scult, M., Wilcher, M., Chudnofsky, R., Malloy, L., Hasheminejad, N., et al. (2012). Integrating a relaxation response-based curriculum into a public high school in Massachusetts. Journal of Adolescence, 35, 325-332, http://dx.doi.org/10.1016/j.adolescence.2011.08.008.

Foster, R. L., \& Park, J. H. (2012). An integrative review of literature examining psychometric properties of instruments measuring anxiety or fear in hospitalized children. Pain Management Nursing, 13, 94-106, http://dx.doi.org/10.1016/j.pmn.2011.06.006.

Go, C., \& Cupertino, P. (2001). Link between delinquency and suicide contemplation in children. San Francisco, CA: American Psychological Association.

Goyal, M., Singh, S., Sibinga, E. M., Gould, N. F., Rowland-Seymour, A., Sharma, R., et al. (2014). Meditation programs for psychological stress and well-being: A systematic review and meta-analysis. JAMA Internal Medicine, 174, 357-368, http://dx.doi.org/10.1001/jamainternmed.2013.13018.

Greenberg, M., \& Harris, A. (2012). Nurturing mindfulness in children and youth: Current state of research. Child Development Perspectives, 6, 161-166.

Gregoski, M. J., Barnes, V. A., Tingen, M. S., Dong, Y., Zhu, H., \& Treiber, F. A. (2012). Differential impact of stress reduction programs upon ambulatory blood pressure among African American adolescents: Influences of endothelin-1 gene and chronic stress exposure. International Journal of Hypertension, 2012, 510291, http://dx.doi.org/10.1155/2012/510291.

Gros, D. F., Antony, M. M., Simms, L. J., \& McCabe, R. E. (2007). Psychometric properties of the State-Trait Inventory for Cognitive and Somatic Anxiety (STICSA): Comparison to the State-Trait Anxiety Inventory (STAI). Psychological Assessment, 19, 369-381.

Grossman, P., Niemann, L., Schmidt, S., \& Walach, H. (2004). Mindfulness-based stress reduction and health benefits. A meta-analysis. Journal of Psychosomatic Research, 57, 35-43.

Grossman, P., \& Van Dam, N. T. (2011). Mindfulness, by any other name. Trials and tribulations of satî in Western psychology and science. Contemporary Buddhism, $12,219-239$.

Hedges, D. W., \& Woon, F. L. (2011). Early-life stress and cognitive outcome. Psychopharmacology, 214, 121-130, http://dx.doi.org/10.1007/s00213-010-2090-6.

Heeren, A., Van Broeck, N., \& Philippot, P. (2009). The effects of mindfulness on executive processes and autobiographical memory specificity. Behaviour Research E' Therapy, 47, 403-409.

Hilt, L. M., Nock, M. K., Lloyd-Richardson, E. E., \& Prinstein, M. J. (2008). Longitudinal study of nonsuicidal self-injury among young adolescents: Rates, correlates, and preliminary test of interpersonal model. Journal of Early Adolescence, 28, 455-469.

Hofmann, S. G., Sawyer, A. T., Witt, A. A., \& Oh, D. (2010). The effect of mindfulness-based therapy on anxiety and depression: A meta-analytic review. Journal of Consulting and Clinical Psychology, 78, 169-183.

Hudziak, J. (1998). DSM-IV Checklist for childhood disorders. Burlington, VT: University of Vermont, Research Center for Children, Youth and Families.

Huppert, F., \& Johnson, D. (2010). A controlled trial of mindfulness training in schools: The importance of practice for an impact on well-being. Journal of Positive Psychology, 5, 264-274.

Ivarsson, T., Gillberg, C., Arvidsson, T., \& Broberg, A. G. (2002). The Youth Self-Report (YSR) and the Depression Self-Rating Scale (DSRS) as measures of depression and suicidality among adolescents. European Child and Adolescent Psychiatry, 11, 31-37.

Jazaieri, H., Goldin, P. R., Werner, K., Ziv, M., \& Gross, J. J. (2012). A randomized trial of MBSR versus aerobic exercise for social anxiety disorder. Journal of Clinical Psychology, 68, 715-731, http://dx.doi.org/10.1002/jclp.21863.

Jennings, P. A., Frank, J. L., Snowberg, K., Coccia, M., \& Greenberg, M. T. (2013). Improving classroom learning environments by Cultivating Awareness and Resilience in Education (CARE): Results of a randomized controlled trial. School Psychology Quarterly, 28, 374-390, http://dx.doi.org/10.1037/spq0000035.

Jennings, P., \& Greenberg, M. (2009). The prosocial classroom: Teacher social and emotional competence in relation to student and classroom outcomes. Review of Educational Research, 79, 491-525.

Jha, A. P., Krompinger, J., \& Baime, M. J. (2007). Mindfulness training modifies subsystems of attention. Cognitive, Affective E Behavioral Neuroscience, 7, 109-119.

Kabat-Zinn, J. (1990). Full catastrophe living: Using the wisdom of your body and mind to face stress, pain, and illness. New York, NY: Random House.

Kaiser-Greenland, S. (2010). The mindful child. New York, NY: Free Press.

Kataoka, S. H., Zhang, L., \& Wells, K. B. (2002). Unmet need for mental health care among U.S. children: Variation by ethnicity and insurance status. American Journal of Psychiatry, 159, 1548-1555.

Kaul, P., Passafiume, J., Sargent, C., \& O'Hara, B. (2010). Meditation acutely improves psychomotor vigilance, and may decrease sleep need. Behavioral and Brain Functions, 6, 47-56.

Keenan, K., Hipwell, A., Feng, X., Babinski, D., Hinze, A., Rischall, M., et al. (2008). Subthreshold symptoms of depression in preadolescent girls are stable and predictive of depressive disorders. Journal of the American Academy of Child and Adolescent Psychiatry, 47, 1433-1442.

Kemeny, M. E., Foltz, C., Cavanagh, J. F., Cullen, M., Giese-Davis, J., Jennings, P., et al. (2012). Contemplative/emotion training reduces negative emotional behavior and promotes prosocial responses. Emotion, 12, 338-350, http://dx.doi.org/10.1037/a0026118.

Kessler, R. C., Berglund, P. A., Bruce, M. L., Koch, J. R., Laska, E. M., Leaf, P. J., et al. (2001). The prevalence and correlates of untreated serious mental illness. Health Services Research, 36, 987-1007.

Khalsa, S., Hickey-Schultz, L., Cohen, D., Steiner, N., \& Cope, S. (2012). Evaluation of the mental health benefits of yoga in a secondary school: A preliminary randomized controlled trial. The Journal of Behavioral Health Services and Research, 39, 80-90, http://dx.doi.org/10.1007/s11414-011-9249-8.

Kirkcaldy, B. D., Eysenck, M., \& Siefen, R. G. (2004). Psychological and social predictors of suicidal ideation among young adolescents. School Psychology International, 25, 301-316.

Kline, R. B. (2013). Beyond significance testing: Statistics reform in the behavioral sciences (2nd ed.). Washington, DC: APA Books.

Kloos, A. L., Collins, R., Weller, R. A., \& Weller, E. B. (2007). Suicide in preadolescents: Who is at risk? Current Psychiatry Reports, 9, 89-93. 
Laye-Gindhu, A., \& Schonert-Reichl, K. (2005). Nonsuicidal self-harm among community adolescents: Understanding the "whats" and "whys" of self-harm. Journal of Youth and Adolescence, 34, 447-457, http://dx.doi.org/10.1007/s10964-005-7262-z.

Leaf, P., Alegria, M., Cohen, P., Goodman, S., Horwitz, S., Hoven, C., et al. (1996). Mental health service use in the community and schools: Results from the fourcommunity MECA study. Journal of the American Academy of Child and Adolescent Psychiatry, 37, 889-897.

Lefevre, J. A., Berrigan, L., Vendetti, C., Kamawar, D., Bisanz, J., Skwarchuk, S. L., et al. (2013). The role of executive attention in the acquisition of mathematical skills for children in grades 2 through 4. Journal of Experimental Child Psychology, 114, 243-261, http://dx.doi.org/10.1016/j.jecp.2012.10.005.

Lessard, J. C., \& Moretti, M. M. (1998). Suicidal ideation in an adolescent clinical sample: Attachment patterns and clinical implications. Journal of Adolescence, 21, 383-395, http://dx.doi.org/10.1006/jado.1998.0169.

Lloyd-Richardson, E. E., Perrine, N., Dierker, L., \& Kelley, M. L. (2007). Characteristics and functions of non-suicidal self-injury in a community sample of adolescents. Psychological Medicine, 37, 1183-1192, http://dx.doi.org/10.1017/S003329170700027X.

Ma, S. H., \& Teasdale, J. D. (2004). Mindfulness-based cognitive therapy for depression: Replication and exploration of differential relapse prevention effects. Journal of Consulting and Clinical Psychology, 72, 31-40.

MacCoon, D. G., Imel, Z. E., Rosenkranz, M. A., Sheftel, J. G., Weng, H. Y., Sullivan, J. C., et al. (2012). The validation of an active control intervention for Mindfulness Based Stress Reduction (MBSR). Behavior Research and Therapy, 50, 3-12, http://dx.doi.org/10.1016/j.brat.2011.10.011.

MacLean, K. A., Ferrer, E., Aichele, S. R., Bridwell, D. A., Zanesco, A. P., Jacobs, T. L., et al. (2010). Intensive meditation training improves perceptual discrimination and sustained attention. Psychological Science, 21, 829-839, http://dx.doi.org/10.1177/0956797610371339.

Marlatt, G., \& Kristeller, J. (1999). Mindfulness and meditation. In W. Miller (Ed.), Integrating spirituality into treatment: Resources for practitioners (pp. 67-84). Washington, DC: American Psychological Association.

McCormack, H. M., Horne, D. J., \& Sheather, S. (1988). Clinical applications of visual analogue scales: A critical review. Psychological Medicine, 18, 1007-1019.

Meiklejohn, J., Phillips, C., Freedman, M., Griffin, M., Biegel, G., Roach, A., et al. (2012). Integrating mindfulness training into K-12 education: Fostering the resilience of teachers and students. Mindfulness, 1, 1-17, http://dx.doi.org/10.1007/s12671-012-0094-5.

Mendelson, T., Greenberg, M. T., Dariotis, J. K., Gould, L. F., Rhoades, B. L., \& Leaf, P. J. (2010). Feasibility and preliminary outcomes of a school-based mindfulness intervention for urban youth. Journal of Abnormal Child Psychology, 38, 985-994, http://dx.doi.org/10.1007/s10802-010-9418-x.

Mercer, J. (2011). Martial arts research: Weak evidence. Science, 334, 310-311.

Merikangas, K. R., He, J. P., Brody, D., Fisher, P. W., Bourdon, K., \& Koretz, D. S. (2010). Prevalence and treatment of mental disorders among US children in the 2001-2004 NHANES. Pediatrics, 125, 75-81, http://dx.doi.org/10.1542/peds.2008-2598.

Metz, S. M., Frank, J. L., Reibel, D., Cantrell, T., Sanders, R., \& Broderick, P. C. (2013). The effectiveness of the learning to BREATHE program on adolescent emotion regulation. Research in Human Development, 10, 252-272.

Miles, M., Huberman, A., \& Saldana, J. (2014). Qualitative data analysis: A methods sourcebook (3rd ed.). Thousand Oaks, CA: Sage Publications.

Mind and Life Education Research Network (MLERN), Davidson, R., Dunne, J., Eccles, J., Engle, A., Greenberg, M., et al. (2012). Contemplative practices and mental training: Prospects for American education. Child Development Perspectives, 6, 146-153, http://dx.doi.org/10.1111/j.1750-8606.2012.00240.x.

Moffitt, T. E., Arseneault, L., Belsky, D., Dickson, N., Hancox, R. J., Harrington, H., et al. (2011). A gradient of childhood self-control predicts health, wealth, and public safety. Proceedings of the National Academy of Sciences of the United States of America, 108, 2693-2698, http://dx.doi.org/10.1073/pnas.1010076108.

Moher, D., Hopewell, S., Schulz, K. F., Montori, V., Gotzsche, P. C., Devereaux, P. J., et al. (2010). CONSORT 2010 explanation and elaboration: Updated guidelines for reporting parallel group randomised trials. Journal of Clinical Epidemiology, 63, e1-e37, http://dx.doi.org/10.1016/j.jclinepi.2010.03.004.

Mularski, R. A., Munjas, B. A., Lorenz, K. A., Sun, S., Robertson, S. J., Schmelzer, W., et al. (2009). Randomized controlled trial of mindfulness-based therapy for dyspnea in chronic obstructive lung disease. Journal of Alternative and Complementary Medicine, 15, 1083-1090.

Napoli, M., Krech, P., \& Holley, L. (2005). Mindfulness training for elementary school students: The attention academy. Journal of Applied School Psychology, 21, 99-123.

Nock, M. K., \& Prinstein, M. J. (2005). Contextual features and behavioral functions of self-mutilation among adolescents. Journal of Abnormal Psychology, 114, 140-146, http://dx.doi.org/10.1037/0021-843X.114.1.140.

Nyklicek, I., \& Kuijpers, K. F. (2008). Effects of mindfulness-based stress reduction intervention on psychological well-being and quality of life: Is increased mindfulness indeed the mechanism? Annals of Behavioral Medicine, 35, 331-340, http://dx.doi.org/10.1007/s12160-008-9030-2.

O'Neil, H., Spielberger, C., \& Hansen, D. (1969). Effects of state anxiety and task difficulty on computer-assisted learning. Journal of Educational Psychology, 60, 343-350.

Ortner, C. M. N., Kilner, S., \& Zelazo, P. D. (2007). Mindfulness meditation and emotional interference in a simple cognitive task. Motivation and Emotion, 31, 271-283.

Paus, T., Keshavan, M., \& Giedd, J. N. (2008). Why do many psychiatric disorders emerge during adolescence? Nature Reviews Neuroscience, 9, 947-957, http://dx. doi.org/10.1038/nrn2513.

Peltzer, K., \& Pengpid, S. (2012). Suicidal ideation and associated factors among school-going adolescents in Thailand. International Journal of Environmental Research and Public Health, 9, 462-473, http://dx.doi.org/10.3390/ijerph9020462.

Perroud, N. (2011). Suicidal ideation during antidepressant treatment: Do genetic predictors exist? CNS Drugs, $25,459-471$.

Perroud, N., Uher, R., Marusic, A., Rietschel, M., Mors, O., Henigsberg, N., et al. (2009). Suicidal ideation during treatment of depression with escitalopram and nortriptyline in genome-based therapeutic drugs for depression (GENDEP): A clinical trial. BMC Medicine, 7, 60.

Pfeffer, C. R. (1997). Childhood suicidal behavior. A developmental perspective. Psychiatric Clinics of North America, $20,551-562$.

Pfeffer, C. R. (2001). Diagnosis of childhood and adolescent suicidal behavior: Unmet needs for suicide prevention. Biological Psychiatry, 49, $1055-1061$.

Pine, D., Cohen, E., Cohen, P., \& Brook, J. (1999). Adolescent depressive symptoms as predictors of adult depression: Moodiness or mood disorder? American Journal of Psychiatry, 156, 133-135.

Pinniger, R., Brown, R. F., Thorsteinsson, E. B., \& McKinley, P. (2012). Argentine tango dance compared to mindfulness meditation and a waiting-list control: A randomised trial for treating depression. Complementary Therapies in Medicine, 20, 377-384, http://dx.doi.org/10.1016/j.ctim.2012.07.003.

QSR International (2002). NVivo qualitative data analysis program (version 10). Melbourne, Australia: Author.

Raes, F., Griffith, J., Van der Gucht, K., \& Williams, J. (2013). School-based prevention and reduction of depression in adolescents: A cluster-randomized controlled trial of a mindfulness group program. Mindfulness, http://dx.doi.org/10.1007/s12671-12013-10202-12671.

Reynolds, C., \& Kamphaus, R. (1992). Behavior assessment system for children. Circle Pines, MN: American Guidance Service.

Roberts-Wolfe, D., Sacchet, M., Hastings, E., Roth, H., \& Britton, W. (2012). Mindfulness training alters emotional memory recall compared to active controls: Support for an emotional information processing model of mindfulness. Frontiers in Human Neuroscience, 6, 1-13, http://dx.doi.org/10.3389/fnhum.2012. 00015.

Rodham, K., \& Hawton, K. (2009). Epidemiology and phenomenology of non-suicidal self-injury. In M. Nock (Ed.), Understanding nonsuicidal self-injury: Origins, assessment, and treatment (pp. 37-62). Washington, D.C.: American Psychological Association.

Roeser, Skinner, Beers, \& Jennings, P. (2012). Mindfulness training and teachers' professional development: An emerging area of research and practice. Child Development Perspectives, 6, 167-173.

Rones, M., \& Hoagwood, K. (2000). School-based mental health services: A research review. Clinical Child and Family Psychology Review, 3, $223-241$.

Ross, S., \& Heath, N. (2002). A study of the frequency of self-mutilation in a community sample of adolescents. Journal of Youth and Adolescence, 31, 67-77.

Roth, H. (2006). Contemplative studies: Prospects for a new field. Columbia Teacher's College Record Special Issue on Contemplative Education, 108, 1787-1816.

Roth, H. (2008). Against cognitive imperialism. Religion East and West, 8, 1-23.

Roth, H. (2011). Contemplative studies: Can it flourish in the religious studies classroom. In J. Simmer-Brown, \& F. Grace (Eds.), Meditation and the classroom: Contemplative pedagogy for religious studies. (pp. 23-38)Albany, NY: SUNY Press.

Roth, H. (2014s). A pedagogy for the new field of contemplative studies. In O. Gunnlaugson, E. W. Sarath, C. Scott, \& H. Bai (Eds.), Contemplative approaches to learning and inquiry across disciplines. Albany, NY: SUNY Press (in press).

Ryff, C. D., Dienberg Love, G., Urry, H. L., Muller, D., Rosenkranz, M. A., Friedman, E. M., et al. (2006). Psychological well-being and ill-being: Do they have distinct or mirrored biological correlates? Psychotherapy and Psychosomatics, 75, 85-95. 
Saltzman, A., \& Goldin, P. (2008). Mindfulness based stress reduction for school-age children. In S. Hayes, \& L. Greco (Eds.), Acceptance and mindfulness interventions for children and adolescents (pp. 139-161). Oakland, CA: Context Press/New Harbinger.

Schlitt, J., Santelli, J., Juszczak, L., Brindis, C., Nystrom, R., Klein, J., et al. (2000). Creating access to care for children and youth: School-Based Health Center Census 1998-1999. Washington, DC: National Assembly on School-Based Health Care.

Schonert-Reichl, K., \& Lawlor, M. S. (2010). The effects of a mindfulness-based education program on pre- and early adolescents' well-being and social and emotional competence. Mindfulness, 1, 137-151.

Schulz, K. F., Altman, D. G., \& Moher, D. (2010). CONSORT 2010 statement: Updated guidelines for reporting parallel group randomized trials. Annals of Internal Medicine, 152, 726-732, http://dx.doi.org/10.7326/0003-4819-152-11-201006010-00232.

Segal, Z., Teasdale, J., \& Williams, M. (2002). Mindfulness-based cognitive therapy for depression. New York, NY: Guilford Press.

Semple, R., Lee, J., Rosa, D., \& Miller, L. (2010). A randomized trial of mindfulness-based cognitive therapy for children: Promoting mindful attention to enhance social-emotional resiliency in children. Journal of Child and Family Studies, 19, 218-229, http://dx.doi.org/10.1007/s10826-009-9301-y.

Shao, J., \& Zhong, B. (2003). Last observation carry-forward and last observation analysis. Statistics in Medicine, 22, 2429-2441, http://dx.doi.org/10.1002/sim. 1519.

Shapiro, S., Brown, K., \& Astin, J. (2011). Toward the integration of meditation into higher education: A review of research evidence. Teachers College Record, 113, 493-528.

Singh, N. N., Lancioni, G., Singh Joy, S., Winton, A., Sabaawi, M., Wahler, R., et al. (2007). Adolescents with conduct disorder can be mindful of their aggressive behavior. Journal of Emotional and Behavioral Disorders, 15, 56-63.

Singh, N. N., Lancioni, G. E., Winton, A. S. W., Karazsia, B. T., \& Singh, J. (2013). Mindfulness training for teachers changes the behavior of their preschool students. Research in Human Development, 10, 211-233.

Singh, N. N., Singh, A., Lancioni, G., Singh, J., Winton, A., \& Adkins, A. (2010). Mindfulness training for parents and their children with ADHD increases the children's compliance. Journal of Child and Family Studies, 19, 157-166, http://dx.doi.org/10.1007/s10826-009-9272-z.

Stoep, A. V., McCauley, E., Flynn, C., \& Stone, A. (2009). Thoughts of death and suicide in early adolescence. Suicide and Life-Threatening Behavior, 39, 599-613, http://dx.doi.org/10.1521/suli.2009.39.6.599.

Tang, Y. Y., Ma, Y., Wang, J., Fan, Y., Feng, S., Lu, Q., et al. (2007). Short-term meditation training improves attention and self-regulation. Proceedings of the National Academy of Sciences of the United States of America, 104, 17152-17156, http://dx.doi.org/10.1073/pnas.0707678104.

Tang, Y., Yang, L., Leve, L., \& Harold, G. T. (2012). Improving executive function and its neurobiological mechanisms through a mindfulness-based intervention: Advances within the field of developmental neuroscience. Child Development Perspectives, 6, 361-366.

Teasdale, J. D., Segal, Z. V., Williams, J. M., Ridgeway, V. A., Soulsby, J. M., \& Lau, M. A. (2000). Prevention of relapse/recurrence in major depression by mindfulnessbased cognitive therapy. Journal of Consulting and Clinical Psychology, 68, 615-623.

Valentine, E., \& Sweet, P. (1999). Meditation and attention: A comparison of the effects of concentrative and mindfulness meditation on sustained attention. Mental Health, Religion, and Culture, 2, 59-70.

Van Dam, N. T., Earleywine, M., \& Borders, A. (2010). Measuring mindfulness? An item response theory analysis of the Mindful Attention Awareness Scale. Personality and Individual Differences, 49, 805-810, http://dx.doi.org/10.1016/j.paid.2010.07.020.

Van Dam, N. T., Hobkirk, A. L., Danoff-Burg, S., \& Earleywine, M. (2012). Mind your words: Positive and negative items create method effects on the Five Facet Mindfulness Questionnaire. Assessment, 19, 198-204, http://dx.doi.org/10.1177/1073191112438743.

van de Weijer-Bergsma, E., Formsma, A., de Bruin, E., \& Bogels, S. (2012). The effectiveness of mindfulness training on behavioral problems and attentional functioning in adolescents with ADHD. Journal of Child and Family Studies, 21, 775-787.

Vander Stoep, A., Adrian, M., McCauley, E., Crowell, S., Stone, A., \& Flynn, C. (2011). Risk for suicidal ideation and suicide attempts associated with co-occurring depression and conduct disorders in early adolescence. Suicide and Life-Threatening Behavior, 41, 316-329.

Wall, R. B. (2005). Tai Chi and mindfulness-based stress reduction in a Boston public middle school. Journal of Pediatric Health Care, $19,230-237$.

Waters, L., Barsky, A., Ridd, A., \& Allen, K. (2014). Contemplative education: A systematic, evidence-based review of the effect of meditation interventions in schools. Educational Psychology Review, http://dx.doi.org/10.1007/s10648-014-9258-2 (published online ahead of print).

Watson, D., Clark, L. A., \& Tellegen, A. (1988). Development and validation of brief measures of positive and negative affect: The PANAS scales. Journal of Personality and Social Psychology, 54, 1063-1070.

Weiner, I., Graham, J., \& Naglieri, J. (Eds.). (2003). Assessment psychology, Vol. 10, . Hoboken, NJ: John Wiley \& Sons.

Weist, M. (1997). Expanded school mental health services: National movement in progress. Advances in Clinical Child Psychology, 19, 319-351.

Wewers, M. E., \& Lowe, N. K. (1990). A critical review of visual analogue scales in the measurement of clinical phenomena. Research in Nursing E Health, 13, $227-236$.

WHO (1948). Preamble to the Constitution of the World Health Organization. New York, NY: World Health Organization.

Wilkinson, L., \& APA Task Force for Statistical Inference (1999). Statistical methods in psychology journals: Guidelines and explanations. American Psychologist, 54, 594-604.

Williams, K. A., \& Chapman, M. V. (2011). Comparing health and mental health needs, service use, and barriers to services among sexual minority youths and their peers. Health E' Social Work, 36, 197-206.

Williams, J. M., Duggan, D. S., Crane, C., \& Fennell, M. J. (2006). Mindfulness-based cognitive therapy for prevention of recurrence of suicidal behavior. Journal of Clinical Psychology, 62, 201-210.

Wood, A. M., \& Joseph, S. (2010). The absence of positive psychological (eudemonic) well-being as a risk factor for depression: A ten year cohort study. Journal of Affective Disorders, 122, 213-217.

Wu, P., Katic, B. J., Liu, X., Fan, B., \& Fuller, C. J. (2010). Mental health service use among suicidal adolescents: Findings from a U.S. national community survey. Psychiatric Services, 61, 17-24, http://dx.doi.org/10.1176/appi.ps.61.1.17.

Zar, J. H. (1999). Biostatistical analysis (4th ed.). Upper Saddle River, NJ: Prentice Hall.

Zeidan, F., Johnson, S. K., Diamond, B. J., David, Z., \& Goolkasian, P. (2010). Mindfulness meditation improves cognition: Evidence of brief mental training. Consciousness and Cognition, 19, 597-605.

Zylowska, L., Ackerman, D. L., Yang, M. H., Futrell, J. L., Horton, N. L., Hale, T. S., et al. (2008). Mindfulness meditation training in adults and adolescents with ADHD: A feasibility study. Journal of Attention Disorders, 11, 737-746, http://dx.doi.org/10.1177/1087054707308502. 